Potravinarstvo Slovak Journal of Food Sciences vol. 13, 2019, no. 1, p. 800-805

https://doi.org/10.5219/1165

Received: 19 July 2019. Accepted: 17 September 2019. Available online: 28 October 2019 at www.potravinarstvo.com (C) 2019 Potravinarstvo Slovak Journal of Food Sciences, License: CC BY 3.0

ISSN 1337-0960 (online)

\title{
LOOP-MEDIATED ISOTHERMAL AMPLIFICATION (LAMP) FOR RAPID DETECTION OF L. MONOCYTOGENES IN MEAT
}

\author{
Yuliya Yushina, Anzhelika Makhova, Elena Zayko, Dagmara Bataeva
}

\begin{abstract}
There is a continued need to develop improved rapid methods for detection of foodborne pathogens. Rapid and sensitive methods for enumeration of Listeria monocytogenes are important for microbiological food safety testing purpose. The aim of this project was to evaluate a commercial loop-mediated isothermal amplification (LAMP) based system with bioluminescence, named as 3M $\mathrm{M}^{\mathrm{TM}}$ Molecular Detection Assay (MDA), was validated for the detection of L. monocytogenes in food products with a standard GOST 32031-2012 method as reference. The results of this study revealed that a commercial LAMP-based method performed equally effective compared with method, showing from $94 \%$ to $100 \%$ specificity and sensitivity, respectively. The LAMP-based method was shown to be rapid and reliable detection technique for L. monocytogenes present at low numbers (10 CFU.g-1) on raw meat and meat products and can be applicable in meat industry. Thus, compared with the microbiological method based GOST 32031-2012, the LAMP assay is a relatively rapid and highly sensitive method for detecting L. monocytogenes and will facilitate the surveillance for contamination of L. monocytogenes in food. The 3M MDS result and culture-based detection (GOST 32031-2012) did not differ significantly $(p>0.05)$ regarding the number of positive samples.
\end{abstract}

Keywords: meat; L. monocytogenes detection; LAMP-method

\section{INTRODUCTION}

Listeria monocytogenes is a pathogen that causes the severe foodborne disease such as listeriosis (Swaminathan and Gerner-Smidt, 2007; Warriner and Namvar, 2009). There is approximately 1600 illnesses and 260 deaths each year are due to listeriosis in USA (Centers for Disease Control and Prevention, 2014). European Food Safety Authority (EFSA) and European Centre for Disease Prevention and Control (ECDC) reported that in 2008 2016 in Europe an increasing trend of human listeriosis cases was observed with 2536 cases of which $97.7 \%$ were hospitalized and $16.2 \%$ were with case fatality (EFSA and ECDC, 2017). A major concern for processors of risk food products is a survive, multiply; persist under harsh conditions in food processing environments (Gandhi and Chikindas, 2007; Carpentier and Cerf, 2011). L. monocytogenes can occur in raw or processed foods that are contaminated during processing. (Koreňová and Oravcová, 2011; Bogdanovičová et al., 2015). It is estimated that more than $99 \%$ of human listeriosis results from consumption of contaminated food, particularly readyto-eat (RTE) foods, such as dairy products, smoked fish (Allerberger and Wagner, 2010; Koch et al., 2010).
Indrawattana et al. (2011) reported that $15.4 \%$ from 104 of the raw meat samples collected from supermarkets and open markets in the Bangkok metropolitan area were contaminated with L. monocytogenes. In Morocco, for instance, L. monocytogenes was present in $2.3 \%$ of 426 poultry and red meat samples collected in 2008 (Ennaji et al., 2008).

The official methods for the detection of this pathogen in foods, are based on culture techniques (Law et al., 2015) are reliable but present disadvantages, such as timeconsuming and lengthy. This is a major drawback of particular importance for food products with short shelf-life, for performing outbreak analysis, and for self-monitoring in production plants (Garrido-Maestu et al., 2017; Shan et al., 2012). The appearance of molecular methods, such as the Polymerase Chain Reaction (PCR), and real-time PCR (qPCR), has allowed to overcome these limitations. More recently, isothermal DNA amplification approaches are gaining interest, being among the most popular loopmediated isothermal amplification (LAMP). It presents several advantages over PCR/qPCR, such as being performed at constant temperature or having higher specificity due to the present of a several number of primers (Abdulmawjood et al., 2016; Wang et al., 2015). LAMP 
can be monitored in real-time by measuring the increase in fluorescence of DNA binding dyes (Seyrig et al., 2015).

The objective of this study was to evaluate the performance of a commercial loop-mediated isothermal DNA amplification (LAMP) based method with bioluminescence named as $3 \mathrm{M}^{\mathrm{TM}}$ Molecular Detection System (MDS) for the detection of L. monocytogenes in raw meat and ready-to-cook (RTC) meat products using the $3 \mathrm{M}^{\mathrm{TM}}$ Molecular Detection Assay (MDA). The study was conducted for the detection of low inoculum levels of $L$. monocytogenes in comparison to the GOST 32031 method to validate LAMP-based method.

\section{Scientific hypothesis}

LAMP-based system provides rapid and reliable results for the detection L. monocytogenes in raw meat and meat products and can be applicable in meat industry. Sensitivity and specificity shold be more than 90\%. Kappa-value should be more than 0.85 .

\section{MATERIAL AND METHODOLOGY}

Raw meat (beef, pork) and meat products (RTE, RTC) were selected as objects of study. Pork ground and beef ground samples were used for artificial contamination and further detection of method sensitivity threshold. All samples were purchased at a local supermarket in central region of Russian Federation from September 2018 through March 2019.

\section{Cultures preparation}

L. monocytogenes ATCC 35152 NCTC 7973 and ATCC 13932 serovars $4 \mathrm{~b}$ (from American Type Culture Collection (Manassas, VA, USA), were activated in $10 \mathrm{~mL}$ of tryptone soya broth (TSB, Oxoid, England) for $24 \mathrm{~h}$ at $37{ }^{\circ} \mathrm{C}$. The cultures were centrifuged (Eppendorf, Germany) at $3000 \mathrm{~g}$ for $10 \mathrm{~min}$, washed twice with $0.1 \%(\mathrm{w} / \mathrm{v})$ peptone water (Oxoid, England), and resuspended in $1 \mathrm{~mL}$ of $0.1 \%(\mathrm{w} / \mathrm{v})$ peptone water (Oxoid, England), and then mixed (1:1, v/v) to prepare a 2-strain cocktail (101 and $10_{2}$ CFU.mL-1). Before inoculation, the counts of prepared 2-strain cocktail of L. monocytogenes diluted in $0.1 \%$ (w/v) PW (Oxoid, England) were enumerated by spread plating an aliquot of $100 \mu \mathrm{L}$ on tryptone soya agar (TSA, Oxoid, England) in duplicate and incubating TSA plates at $37{ }^{\circ} \mathrm{C}$ for $48 \mathrm{~h}$ to estimate the inoculum levels.

\section{Inoculation procedure}

There were two inoculation levels for matrix: a high inoculation level of approximately 100 CFU.g-1 and a low inoculation level of approximately 10 CFU.g-1. Also was used uninoculated samples as negatives controls.

\section{L. monocytogenes detection with a commercial lamp-based system}

The detection of $L$. monocytogenes cells by the commercial LAMP-based kit (3M Molecular Detection Assay Listeria monocytogenes; 3M) was performed according to the manufacturer's manual. Briefly, $25 \mathrm{~g}$ of sample were mixed with $225 \mathrm{ml}$ Demi-Fraser broth (3M, USA). Then $20 \mu \mathrm{L}$ of UVM enrichment was added to a tube with lysis solution. The mixture was warmed in a heat block
(Germany, IKA) at $100{ }^{\circ} \mathrm{C}$ for $15 \mathrm{~min}$, followed by immediate cooling at room temperature in a chilling block (3M, USA) for $10 \mathrm{~min}$. After mixing by inversion, $20 \mu \mathrm{L}$ of this lysate was mixed with the pellet in the reagent tube from the assay kit. The reagent tube was placed in a molecular detection system (3M, U.S.A.) for the detection of $L$. monocytogenes cells via isothermal amplification and bioluminescence for $75 \mathrm{~min}$. All analyses included negative and reagent controls to validate the performance of the molecular detection system.

\section{Detection L. monocytogenes by GOST 32031}

The samples were examined for the presence of $L$. monocytogenes bacteria in accordance with GOST 320312012. $25 \mathrm{~g}$ of the meat was homogenized in $225 \mathrm{~cm}_{3}$ of Demi-Fraser broth (Merck, Germany) and incubated at $30{ }^{\circ} \mathrm{C}$ for 24 hours. Then $0.1 \mathrm{~cm}_{3}$ the enriched culture was added to $10 \mathrm{~cm} 3$ of Fraser's broth (Merck, Germany) and cultured at $37^{\circ} \mathrm{C}$ for 48 hours. From each broth after the end of incubation with a $3 \mathrm{~mm}$ loop, the enriched material was streaked onto a chromogenic agar for Listeria (Agar Listeria according to Ottaviani and Agost (Merck, Germany)) and selective nutrient agar for Listeria PAL (FBUN GNC PMB, Russia) and incubated at $37{ }^{\circ} \mathrm{C}$ within $24-48$ hours. On chromogenic agar for Listeria, L. monocytogenes grows in the form of blue colonies with an area around; on PAL, brown colonies with black halos. Colonies typical of the genus Listeria and L. monocytogenes were seeded on tryptone soya agar with yeast extract (TSAYE) and incubated at $37{ }^{\circ} \mathrm{C}$ for $18-24$ hours, which was then confirmed using biochemical tests (Oxoid, England).

\section{Statistic analysis}

Sensitivity and specificity of the commercial LAMPbased kit for the detection of $L$. monocytogenes were defined as the number of samples truly positive ( $\left.\mathrm{T}_{\mathrm{pos}}\right)$ and truly negative $\left(\mathrm{T}_{\mathrm{neg}}\right)$, respectively, compared with the GOST method. The sensitivity, specificity, and accuracy of the commercial LAMP based kit were calculated as follows:

Sensitivity $=\left[\mathrm{T}_{\mathrm{pos}} /\left(\mathrm{T}_{\mathrm{pos}}+\mathrm{F}_{\mathrm{pos}}\right)\right]$

Specificity $=\left[\mathrm{T}_{\text {neg }} /\left(\mathrm{T}_{\text {neg }}+\mathrm{F}_{\text {neg }}\right)\right]$

where $\mathrm{T}_{\mathrm{Pos}}$ and $\mathrm{T}_{\mathrm{Neg}}$ are the number of positive and negative samples, respectively, confirmed by both the GOST and commercial LAMP-based kit, and $F_{p o s}$ and $F_{n e g}$ are the number of positive and negative samples, respectively, confirmed by the commercial LAMP-based kit. Kappa value of concordance, describing the statistical agreement between the two detection methods was calculated, as described. Kappa values were classified as follows: 0.01 indicated no concordance; 0.1 to 0.4 indicated weak concordance; 0.41 to 0.60 indicated clear concordance; 0.61 to 0.80 indicated strong concordance; and 0.81 to 1.00 indicated nearly complete agreement.

A chi-square test (AOAC, Official Methods of Analysis Program Manual) for significant difference was used to determine whether the proportion of positive samples was different between the 3M MDS and the GOST-method. 


\section{RESULTS AND DISCUSSION}

L. monocytogenes can multiply over a wide range of $\mathrm{pH}$ and osmolarity, at low temperatures, and both under aerobic and anaerobic conditions, this is a particular concern and necessitates control along the food chain.

A wide variety of culture and alternative methods have been developed in order to detect or quantify this pathogen in food. In this study, the effectiveness of the commercial LAMP-based kit was evaluated in comparison to the standard culture GOST method for quickly detection of $L$. monocytogenes on different food matrices as artificially contained so and naturally contained.

In this study, a 2-strain cocktail of Listeria monocytogenes was used for the detection sensitivity threshold.

\section{L. monocytogenes detection in artificial contamination samples}

At the inoculum levels of $10_{1}$ and $10_{2}$ CFU.g-1 both methods abled the detection of L. monocytogenes in all samples (Table 1), resulting in $100 \%$ specificity and sensitivity (kappa value 1). At the inoculum level of $10_{0}$ CFU.g-1 (not uninoculated L. monocytogenes), both methods were unable to detect $L$. monocytogenes. False negative results were not obtained.
L. monocytogenes detection in samples with native microflora (raw meat and meat products, purchased in local supermarkets)

The results samples show high specificity of the LAMPmethod (not less than 90\%) (Table 2). The 3M MDS result and culture-based detection (GOST 32031-2012 method) did not differ significantly $(p>0.05)$ regarding the number of positive samples.

In similar studies, the high specificity and sensitivity of the method on artificially infected matrices has also been proven. L. monocytogenes was detected in 11 samples of pork by LAMP - method and in 10 samples by GOST 32031. One sample was not confirmed according to the reference method and was identified as false-positive ( $\left.F_{p o s}\right)$. The sensitivity of the method in the study of pork samples was $90 \%$ (Kappa value 0.93 ), specificity $-100 \%$.

In another study the LAMP-GNP/DNA probe assay was applied to the detection of 200 raw chicken meat samples and compared to routine standard methods. The data revealed that the specificity, sensitivity, and accuracy were 100, 90.20, and $97.50 \%$, respectively (Wachiralurpan et al., 2018).

Also, in the study of 32 samples of beef ready-to-cook products, 1 false positive result was found by the LAMP method. The sensitivity and specificity of the method were $88 \%$ and $100 \%$, respectively, with a Kappa-value of 0.92 .

Table 1 Comparison of LAMP-based method and GOST-method for the detection L. monocytogenes in artificial contamination samples.

\begin{tabular}{|c|c|c|c|c|c|c|c|c|}
\hline \multirow{2}{*}{$\begin{array}{c}\text { Level } \\
\text { Inoculated } \\
\text { (CFU.g-1) }\end{array}$} & \multirow[b]{2}{*}{ Matrix } & \multicolumn{2}{|c|}{ LAMP and GOST } & \multicolumn{2}{|c|}{ LAMP } & \multirow{2}{*}{$\begin{array}{c}\text { Sensitivity } \\
(\%)\end{array}$} & \multirow{2}{*}{$\begin{array}{c}\text { Specificity } \\
(\%)\end{array}$} & \multirow[b]{2}{*}{ Kappa } \\
\hline & & T-pos & T-neg & F-pos & F-neg & & & \\
\hline \multirow[t]{2}{*}{100} & $\begin{array}{c}\text { Raw ground } \\
\text { beef }\end{array}$ & $0 / 5$ & $0 / 5$ & $0 / 5$ & $0 / 5$ & 100 & 100 & 1 \\
\hline & $\begin{array}{c}\text { Raw groud } \\
\text { pork }\end{array}$ & $0 / 5$ & $0 / 5$ & $0 / 5$ & $0 / 5$ & 100 & 100 & 1 \\
\hline \multirow[t]{2}{*}{101} & $\begin{array}{c}\text { Raw ground } \\
\text { beef }\end{array}$ & $5 / 5$ & $5 / 5$ & $5 / 5$ & $5 / 5$ & 100 & 100 & 1 \\
\hline & $\begin{array}{c}\text { Raw groud } \\
\text { pork }\end{array}$ & $5 / 5$ & $5 / 5$ & $5 / 5$ & $5 / 5$ & 100 & 100 & 1 \\
\hline \multirow[t]{2}{*}{102} & $\begin{array}{c}\text { Raw ground } \\
\text { beef }\end{array}$ & $5 / 5$ & $5 / 5$ & $5 / 5$ & $5 / 5$ & 100 & 100 & 1 \\
\hline & $\begin{array}{c}\text { Raw groud } \\
\text { pork }\end{array}$ & $5 / 5$ & $5 / 5$ & $5 / 5$ & $5 / 5$ & 100 & 100 & 1 \\
\hline
\end{tabular}

Note: T-pos, T-neg are true positive and negative samples, confirmed by both GOST and LAMP-based methods; F-pos and F-neg are false positive and negative samples, confirmed only by LAMP-based technique or GOST method, respectively.

Table 2 Comparison of LAMP-based method and GOST-method for the detection L. monocytogenes in native contamination samples.

\begin{tabular}{|c|c|c|c|c|c|c|c|}
\hline \multirow{2}{*}{ Food matrix } & \multicolumn{2}{|c|}{ LAMP and GOST } & \multicolumn{2}{|c|}{ LAMP } & \multirow{2}{*}{$\begin{array}{c}\text { Sensitivity } \\
(\%)\end{array}$} & \multirow{2}{*}{$\begin{array}{c}\text { Specificity } \\
(\%)\end{array}$} & \multirow{2}{*}{ Kappa } \\
\hline & T-pos & T-neg & F-pos & F-neg & & & \\
\hline pork & 10 & 25 & 1 & 0 & 90 & 100 & 0.93 \\
\hline beef & 5 & 18 & 0 & 1 & 100 & 94 & 0.88 \\
\hline RTC pork & 3 & 16 & 0 & 0 & 100 & 100 & 1 \\
\hline RTC beef & 8 & 24 & 1 & 0 & 88 & 100 & 0.92 \\
\hline RTE & 1 & 16 & 0 & 0 & 100 & 100 & 1 \\
\hline
\end{tabular}

Note: T-pos, T-neg are true positive and negative samples, confirmed by both GOST and LAMP-based methods; F-pos and

F-neg are false positive and negative samples, confirmed only by LAMP-based technique or GOST method, respectively. 
In this case a false positive result could be caused by the DNA amplification on injured or sub lethally cells that cannot be detected by ISO (Lim et al., 2015). Another explanation for false positive results is the using of 4 to 6 primers with a much higher concentration in the LAMP method than in the classical methods based on PCR. In terms of efficiency, the PCR and real-time PCR assays could detect $L$. monocytogenes based on the listeriolysin $\mathrm{O}$ gene $(h l y)$ with a detection limit of $8-10$ CFU (Rip and Gouws, 2009). However, these assays required sophisticated equipment and post-amplification manipulations that took more time to obtain results (Gianfranceschi et al., 2014).

This could lead to an increase in the possibility of nonspecific amplification caused by forming primer dimers (Wang et al., 2015). 23 samples of beef were analysed. 5 positive and 18 negative results were detected and confirmed by both research methods (GOST and LAMP). However, 1 sample was false negative by LAMP-based method compared with GOST 32031-2012. The sensitivity of the method in the study of beef in this case was $100 \%$ (Kappa value 0.88), and the specificity - 94\%. In other studies, false negative results were also obtained (Lim et al., 2015). These authors showed that 1 naturally contaminated sample of duck wings was presented as falsenegative. The validation study also showed $91 \%$ sensitivity and $95 \%$ specificity, Kappa-value 1.

In the study of 19 ready-to-cook pork samples and 17 meat ready-to-eat products, no significant $(p>0.05)$ differences in the results obtained by the LAMP and GOST 32031-2012 methods were found. The sensitivity and specificity of both methods was $100 \%$ with Kappa-value 1. Such a convergence of the two methods can be associated with an enough viable cells of $L$. monocytogenes in the sample to identify them.

Several false-positive and false-negative results were obtained at low levels of inoculum $\left(10{ }_{1} \mathrm{CFU} / 10 \mathrm{~cm} 2\right)$, for the LAMP method have been reported (Mikš-Krajnik et al., 2015). It also reports at a $10_{2} \mathrm{CFU} / 100 \mathrm{~cm} 2$ microbial cell level, both methods were suitable for detection of $L$. monocytogenes and had $100 \%$ specificity and sensitivity.

In another study the LAMP method was employed to test 94 retail food samples effectively. Sensitivity in detection of $L$. monocytogenes by the LAMP was higher than that of PCR and none of the conventional method positive samples was missed by the LAMP method (Shan et al., 2012).

Listeriosis outbreaks were seen in many countries including Japan, the United States and countries of Europe (EFSA, 2011; Miya et al., 2015; Self et al., 2019). Human infections caused by $L$. monocytogenes have become a global health concern. The presence of L. monocytogenes in processing environment at slaughterhouses, deli meat factories or in retail may be a reason of cross-contamination. Listeria monocytogenes can contaminate various foods via food processing environments and contamination of raw materials. Hence, there is a necessity a variety of methods for rapid detection of foodborne pathogens as it is required in many food analyses.

In this study rapid LAMP method of L. monocytogenes detection was performed. Despite the having of falsenegative and false-positive results, LAMP-based method was effective and easier to perform than some of standardized assays and has the advantage to reduce analysis time (less 2 days comparing with 5 days GOST method). Furthermore, this technique is 10 times more sensitive than the conventional PCR assay as reported (Wachiralurpan et al., 2017). The occurrence of falsepositive results can be reduced by preventing crosscontamination, high humidity and temperature when working with reaction mixture tubes (Bird et. al.,2013, Wang et al., 2015).

\section{CONCLUSION}

The results of this study revealed that a commercial LAMP-based method performed equally effective compared with method, showing from $94 \%$ to $100 \%$ specificity and sensitivity, respectively. The LAMP-based method was shown to be rapid and reliable detection technique for L. monocytogenes present at low numbers (10 CFU.g-1) on raw meat and meat products and can be applicable in meat industry. Loop-mediated isothermal amplification (LAMP) has become a powerful alternative to polymerase chain reaction (PCR) for pathogen detection in food matrices.

\section{REFERENCES}

Abdulmawjood, A., Wickhorst, J., Hashim, O., Sammra, O., Hassan, A., Alssahen, M., Lämmler, C., Prenger-Berninghoff, E., Kleina, G. 2016. Application of a loop-mediated isothermal amplification (LAMP) assay for molecular identification of Trueperella pyogenes isolated from various origins. Molecular and Cellular Probes, vol. 30, no. 4, p. 205-210. https://doi.org/10.1016/j.mcp.2016.05.003

Allerberger, F., Wagner, M. 2010. Llisteriosis: A Resurgent Foodborne Infection. Clinical Microbiology and Infection, vol. 16 , no. 1, p. 16-23. https://doi.org/10.1111/j.14690691.2009.03109.x

Bird, P., Fisher, K., Boyle, M., Huffman, T., Benzinger, M. J. Jr., Bedinghaus, P., Flannery, J., Crowley, E., Agin, J., Goins, D., Benesh, D., David, J. 2013. Evaluation of 3M molecular detection assay (MDA) Salmonella for the detection of Salmonella in selected foods: collaborative study. AOAC International, vol. 96, no. 6, p. 1325-1335. https://doi.org/10.5740/jaoacint.13-227

Bogdanovičová, K., Skočková, A., Št'ástková, Z., Koláčková, I., Karpíšková, R. 2015. The bacteriological quality of goat and ovine milk. Potravinarstvo Slovak Journal of Food Sciences, vol. 9, no. 1, p. 72-76. https://doi.org/10.5219/438

Carpentier, B., Cerf, O. 2011. Review - Persistence of Listeria monocytogenes in food industry equipment and premises. International Journal of Food Microbiology, vol. 145, no. $1, \quad$ p. $1-8$ https://doi.org/10.1016/j.ijfoodmicro.2011.01.005

EFSA. 2011. Analysis of the baseline survey on the prevalence of Listeria monocytogenes in certain ready-to-eat foods in the European Union, 2010-2011. Part A: Listeria monocytogenes prevalence estimates. EFSA Journal, vol. 11, no. 6, 75 p. https://doi.org/10.2903/j.efsa.2013.3241

EFSA and ECDC. 2017. The European Union summary report on trends and sources of zoonoses, zoonotic agents and food-borne outbreaks in 2016. EFSA Journal, vol. 15, no. 12, 228 p. https://doi.org/10.2903/j.efsa.2017.5077

Ennaji, H., Timinouni, M., Ennaji, M., Hassar, M., Cohen, N. 2008. Characterization and antibiotic susceptibility of Listeria monocytogenes isolated from poultry and red meat in Morocco. Infection and drug resistance, vol. 2008, no. 1, p. 45-50. https://doi.org/10.2147/IDR.S3632 
Feldsine, P., Abeyta, C., Andrews, W. H. 2002. AOAC International methods committee guidelines of validation of qualitative and quantitative food microbiological official methods of analysis. J. AOAC Int., vol. 85, p. 1187-1200.

Gandhi, M., Chikindas, M. L. 2007. Listeria: A foodborne pathogen that knows how to survive. International Journal of Food Microbiology, vol. 113, no. 1, p. 1-15 https://doi.org/10.1016/j.ijfoodmicro.2006.07.008

Garrido-Maestu, A., Azinheiro, S., Carvalho, J., AbaldeCela, S., Carbó-Argibay, E., Diéguez, L., Prado, M. 2017. Combination of Microfluidic Loop-Mediated Isothermal Amplification with Gold Nanoparticles for Rapid Detection of Salmonella spp. in Food Samples. Frontiers in Microbiology, vol. 8, p. 2159. https://doi.org/10.3389/fmicb.2017.02159

Gianfranceschi, M. V., Rodriguez-Lazaro, D., Hernandez, M., González-García, P., Comin, D., Gattuso, A., Delibato, E., Sonnessa, M., Pasquali, F., Prencipe, V., Sreter-Lancz, T., Saiz-Abajo, M. J., Pérez-De-Juan, J., Butrón, J., Kozačinski, L., Tomic, D. H., Zdolec, N., Johannessen, G. S., Jakočiūnè, D., Olsen, J. E., De Santis, P., Lovari, S., Bertasi, B., Pavoni, E., Paiusco, A., De Cesare, A., Manfreda, G., De Medici, D. 2014. European validation of a real-time PCR-based method for detection of Listeria monocytogenes in soft cheese. Int. J. Food Microbiol., vol. $\quad 184, \quad 128-133$. https://doi.org/10.1016/j.ijfoodmicro.2013.12.021

GOST 32031-2012. Food products. Methods for detection of Listeria monocytogenes.

Indrawattana, N., Nibaddhasobon, T., Sookrung, N., Chongsa-Nguan, M., Tungtrongchitr, A., Makino, S., Tungyong, W., Chaicumpa, W. 2011. Prevalence of Listeria monocytogenes in raw meats marketed in Bangkok and characterization of the isolates by phenotypic and molecular methods. Journal of Health Population and Nutrition, vol. 29, no. 1, p. 26-38. https://doi.org/10.3329/jhpn.v29i1.7565

Koch, J., Dworak, R., Prager, R., Becker, B., Brockmann, S., Wicke, A., Wichmann-Schauer, H., Hof, H., Werber, D., Stark, K. 2010. Large listeriosis outbreak linked to cheese made from pasteurized milk, Germany, 2006-2007. Foodborne pathogens and diseases, vol 7, no. 12, p. 1581-1584. https://doi.org/10.1089/fpd.2010.0631

Koreňová, J., Oravcová, K. 2011. Persistence of 1. monocytogenes versus adherence on solid surface. Potravinarstvo, vol. 5, no. 2, p. 41-44. https://doi.org/10.5219/135

Law, J. W., Ab Mutalib, N. S., Chan, K. G., Lee, L. H. 2015. Rapid methods for the detection of foodborne bacterial pathogens: principles, applications, advantages and limitations. Frontiers in Microbiology, vol. 5, p. 770. https://doi.org/10.3389/fmicb.2014.00770

Lim, H. S., Zheng, Q., Miks-Krajnik, M., Turner, M., Yuk, H. G. 2015. Evaluation of commercial kit based on loopmediated isothermal amplification for rapid detection of low levels of uninjured and injured Salmonella on duck meat, bean sprouts, and fishballs in Singapore. J. Food Prot., vol. 78, no. 6, p. 1203-1207. https://doi.org/10.4315/0362-028X.JFP-14$\underline{535}$

Mikš-Krajnik, M., Lim, H., Zheng, Q., Turner, M., Yuk, H. 2015. Loop-mediated isothermal amplification (LAMP) coupled with bioluminescence for the detection of Listeria monocytogenes at low levels on food contact surfaces. Food $\begin{array}{llll}\text { Control, } & \text { no. } & 60, & \text { p. }\end{array}$ https://doi.org/10.1016/j.foodcont.2015.07.035

Miya, S., Takahashi, H., Nakagaw, M., Kuda, T., Igimi, S., Kimura, B. 2015. Genetic Characteristics of Japanese Clinical Listeria monocytogenes Isolates. PLoS One, vol. 10. https://doi.org/10.1371/journal.pone.0122902
Rip, D., Gouws, P. A. 2009. Development of an internal amplification control using multiplex PCR for the detection of Listeria monocytogenes in food products. Food Anal. Methods, vol. 2, p. 190-196. https://doi.org/10.1007/s12161-009-9081-4

Seyrig, G., Stedtfeld, R. D., Tourlousse, D. M., Ahmad, F., Towery, K., Cupples, A. M., Tiedje, J. M., Hashsham, S. A. 2015. Selection of fluorescent DNA dyes for real-time LAMP with portable and simple optics. J. Microbiol. Methods, vol. 119, p. 223-227. https://doi.org/10.1016/j.mimet.2015.11.004

Self, J. L., Conrad, A., Stroika, S., Jackson, A., Whitlock, L., Jackson, K. A., Beal, J., Wellman, A., Fatica, M. K., Bidol, S., Huth, P. P., Hamel, M., Franklin, K., Tschetter, L., Kopko, C., Kirsch, P., Wise, M. E., Basler, C. 2019. Multistate Outbreak of Listeriosis Associated with Packaged Leafy Green Salads, United States and Canada, 2015-2016. Emerging Infectious Diseases, vol. $25 . \quad$ no. 8, p. 1461-1468. https://doi:10.3201/eid2508.180761

Shan, X., Zhang, Y., Zhang, Z., Chen, M., Su, Y., Yuan, Y., Jahangir Alam, M., Yan, H., Shi, L. 2012. Rapid Detection of Food-borne Listeria monocytogenes by Real-time Quantitative Loop-mediated Isothermal Amplification. Food science and biotechnology, vol. 21, no. 1, p. 101-106. https://doi.org/10.1007/s10068-012-0012-6

Swaminathan, B., Gerner-Smidt, P. 2007. The Epidemiology of Human Listeriosis. Microbes and Infection, vol. 9, no. 10, p. 1236-1243. https://doi.org/10.1016/j.micinf.2007.05.011

Centers for Disease Control and Prevention. 2014.

Wachiralurpan, S., Sriyapai T., Areekit S., Kaewphinit T., Sriyapai, P., Santiwatanakul, S., Chansiri, K. 2017. Development of a rapid screening test for Listeria monocytogenes in raw chicken meat using loop-mediated isothermal amplification (LAMP) and Lateral Flow Dipstick (LFD). Food Anal. Methods, vol. 10, no. 11, p. 3763-3772. https://doi.org/10.1007/s12161-017-0949-4

Wachiralurpan, S., Sriyapai, T., Areekit, S., Sriyapai, P., Augkarawaritsawong, S., Santiwatanakul, S., Chansiri, K. 2018. Rapid Colorimetric Assay for Detection of Listeria monocytogenes in Food Samples Using LAMP Formation of DNA Concatemers and Gold Nanoparticle-DNA Probe Complex. Front. Chem., vol. 6. https://doi.org/10.3389/fchem.2018.00090

Wang, Y., Wang, Y., Luo, L., Liu, D., Luo, X., Xu, Y., Hu, S., Niu, L., Xu, J., Ye, C. 2015. Rapid and Sensitive Detection of Shigella spp. and Salmonella spp. by Multiple Endonuclease Restriction Real-Time Loop-Mediated Isothermal Amplification Technique. Frontiers in microbiology, vol. 6. https://doi.org/10.3389/fmicb.2015.01400

Warriner, K., Namvar, A. 2009. What is the hysteria with Listeria? Trends in Food Science \& Technology, vol. 6, no. 20, p. 245-254. https://doi.org/10.1016/j.tifs.2009.03.008

\section{Contact address:}

Yuliya Yushina, V. M. Gorbatov Federal Research Center for Food Systems of Russian Academy of Sciences, Department of hygiene of production and microbiology, Talalikhina st. 26, 109316, Moscow, Russia, Tel.: 8-916433-51-99,

E-mail: yshinauk@mail.ru

ORCID: https://orcid.org/0000-0001-9265-5511

*Anzhelika Makhova, V. M. Gorbatov Federal Research Center for Food Systems of Russian Academy of Sciences, Department of hygiene of production and microbiology, Talalikhina st. 26, 109316, Moscow, Russia, Tel.:8-916570-91-79,

E-mail: aeremtsova@gmail.com 
ORCID: https://orcid.org/0000-0002-2508-2888

Elena Zayko, V. M. Gorbatov Federal Research Center for Food Systems of Russian Academy of Sciences, Department of hygiene of production and microbiology, Talalikhina st. 26, 109316, Moscow, Russia, Tel.:8-960548-71-95,

E-mail: el.zaiko@yandex.ru

ORCID: https://orcid.org/0000-0002-5048-9321
Dagmara Bataeva, V. M. Gorbatov Federal Research Center for Food Systems of Russian Academy of Sciences, Department of hygiene of production and microbiology, Talalikhina st. 26, 109316, Moscow, Russia, Tel.:8-985663-84-06,

E-mail: b.dagmara@inbox.ru

ORCID: https://orcid.org/0000-0002-1374-2746

Corresponding author: * 